\title{
CSCW - A challenge to certain (G)DSS perspectives on the role of decisions, information, and technology in organizations?
}

\author{
L. J. Bannon \\ Interaction Design Centre \\ Department of Computer Science and Information Systems \\ University of Limerick, \\ Limerick, Ireland \\ Tel:+353-61-202632, Fax: +353-61-202572 \\ e-mail: liam.bannon@ul.ie
}

\begin{abstract}
This paper initiates a dialogue between two related, yet distinct research communities investigating the use of information technology to support work activities - GDSS and CSCW. The paper discusses a number of issues concerning the conceptual framework underpinning work in the area of Group Decision Support Systems (GDSS). It then examines a particular body of work within GDSS, namely that of the Arizona MIS group, who have developed one of the most well-known GDSS environments - Group Systems. This approach is then critiqued, in the light of concerns within the CSCW field. The intent of the paper is not simply to critique certain approaches but to re-frame certain key concerns in the field of decision support, and more specifically, group decision support. In conclusion, the paper suggests several topics that both the GDSS and CSCW community might usefully study.
\end{abstract}

\section{Keywords}

Group decision support systems, computer supported co-operative work, electronic meetings, decision-making, talk, groups, anonymity

\footnotetext{
An initial version of this invited paper was presented at the IFIP WG 8.3 Working Conference on Decision Support in Organizational Transformation in San Sebastian, Spain, Sept, 4-9th 1994 and appears in the Proceedings of that Conference. Portions of the paper subsequently appeared at the 5th European Conference on Information Systems (Bannon, 1997). This is an updated version of the 1994 paper.
} 
"Decisions in organisations involve an ecology of actors trying to act rationally with limited knowledge and preference coherence; trying to discover and execute proper behaviour in ambiguous situations; and trying to discover, construct, and communicate interpretations of a confusing world."

James March, 1991

\section{INTRODUCTION}

The intent of this paper is to initiate a dialogue between two research communities that appear at times to be oblivious to each other, namely the decision-support system (DSS) community, more especially that subset concerned with group DSS (GDSS), and the computer supported co-operative work (CSCW) community. I realise that any attempt such as this is fraught with difficulties, as one is liable to be criticised by members of both communities for not arguing their respective cases properly. Indeed, the whole topic of my presentation may seem premature or illjudged, as both the "fields" of CSCW and GDSS are poorly defined and the terms as we shall see are often used quite loosely, so attempting to set them up as distinct approaches may seem ill-advised. While I recognise that there are many differing perspectives' on the object of research and appropriate conceptualisations within the two communities, for the purposes of my arguments here I will at times characterise work in CSCW and GDSS in somewhat simplified ways. I have attempted to initiate the dialogue in a somewhat controversial fashion, namely by critiquing a single body of influential GDSS work from a CSCW perspective, thus inevitably ignoring other, sometimes radically different, GDSS approaches. My rationale is simply that the GDSS work cited is known to me, and to many in the CSCW community, whilst other GDSS approaches are, perhaps unfortunately, not so familiar. This obviously results in a biased view of the range of approaches extant in GDSS, and the lessons that the CSCW community in turn could learn from such GDSS approaches. I am quite aware that there are many important aspects of DSS and GDSS research from which the CSCW community could and should learn, but as I am not an expert in their field, I have not been able to present the complementary arguments in this paper. So what is presented here is only really half the story, but perhaps it can serve as a spur to efforts to initiate further discussion among GDSS and CSCW researchers, so that we can both learn from each other. Failure to engage in such a dialogue may result in both "fields" atrophying, due to their "closed" community walls.

For many in the CSCW community, (G)DSS - as exemplified by the papers that occasionally appear in CSCW conferences - is still seen as a field of study that relies too heavily on a set of overly rationalistic assumptions about human

For example, I have discussed some of the different perspectives on CSCW that coexist within that community in Bannon (1993). 
behaviour in organisations, focusing on economic and psychological models, whose experimental studies are conducted in laboratory settings involving too much reliance on artificial tasks and student subjects. In contrast, I would hazard a guess that from the perspective of (G)DSS, the CSCW field is seen as relying too much on either political - sociological or ethnomethodological approaches to the study of phenomena, over-emphasising ecological validity relative to experimental rigour in its social science studies, or alternatively having an overly technocentric focus, lacking in theoretical sophistication.

The intent of this paper is to present my view on work in (G)DSS and its attendant problems, then show how some work within $\mathrm{CSCW}$ might usefully provide alternative perspectives for viewing some of these problems, and conclude with a set of research topics that might engage both communities. The argument here is not to argue for the primacy of any particular perspective, although as researchers, we each have our preferred viewpoint, but to enlarge the universe of discourse about the observable behaviours of people in organisations and our understanding of them. For instance, it is my belief that one area where CSCW can contribute is in the discovery and description of the different ontologies and epistemologies of participants in organisations. Perhaps in our uncovering of such differences, we can contribute to a better understanding of how organisations function, and thus contribute to.the theme of how to bring about organisational transformation.

The structure of this paper is as follows. In order to put my remarks in context, I provide a personal and necessarily biased outline and critique on some of the work in the (G)DSS field, focusing on some of the underlying assumptions that appear to be built into the set of tools, techniques, and methodologies of the area. This is followed by a short outline of some key features of the CSCW field, again from a personal perspective, showing what is possibly new about the idea of computer "support" for co-operative activities, and its potential relevance for (G)DSS. Finally, I outline some topics for a programme of research that could provide a basis for useful (G)DSS - CSCW interaction.

\section{THE CONCEPTS OF DECISION-MAKING AND DECISION SUPPORT}

Models from mainstream economics, decision theory and "cognitive sciences" are not - and must not - be the only kinds of intellectual approaches which can help to grapple with the problems of the (re-) organisation of work and the (re-)allocation of resources. (Kjargaard, 1989)

The purpose of this section is to make explicit some of my assumptions about work in the fields of decision-making and decision support, as a frame for my forthcoming critique of certain (G)DSSs later in the paper. What seems to be 
covered under the umbrella term of "decision support systems" (DSS) includes information technology applications that "support" people in making choices about what actions to take in organisations. Thus the area subsumes much of what is often termed management information systems (MIS) and executive information systems (EIS). In some cases, there is an interest in having the systems operate as "decision systems" rather than "decision support systems", as witnessed by some strands of work in the area of expert systems or what is called, more neutral, knowledge-based systems (KBS) where artificial intelligence is used to augment decision making. The basic constituents of these systems are a model base that provides some form of representation for a particular domain, and an interface that allows the user to interact with the system. Concerns centre around the veracity of information in the model, and the quality of the human-computer interface. In many cases, these systems serve as a top-layer of a larger information systems infrastructure containing databases of information about a domain, and the system provides support for the manager to "drill down" into the data and examine relationships between aspects of the data in interesting ways.

Much of the work in the DSS area that I have encountered has tended to rely on a conception of individual problem-solving and decision making heavily influenced by ideas from cognitive psychology, especially the work of Herb Simon, who in his own work, and subsequent collaborations with people such as James March and Allen Newell, developed a comprehensive framework for understanding problemsolving activity - involving notions of representations of problem spaces, and search strategies through these problem spaces. In this approach, people are viewed as information processing mechanisms, and decisions are made by people making rational choices between differently weighted alternatives. While subsequent work, by Simon himself, developed the concept of "bounded rationality" so as to account for the fact that human decision makers could not always be modelled as having perfect information, or utilising optimal strategies, this particular view of decision making as an aspect of problem-solving, of problem-solving as consisting of search through state spaces, of humans as information processors, etc., coupled with a number of conceptions about Homo economicus concerning maximisation of expected utility, preference functions, etc. has held sway for almost half a century in the cognitive science field. The upshot of this work has been a generally accepted set of conventions about how people make decisions, and about the way in which information systems might "support" this process through providing access to the appropriate kinds and levels of information and problem representations that decision-makers require in order to be able to make good decisions. The research work undertaken by this programme has covered such areas as studies of behavioural decision making, the development of appropriate models, and the improvement of the quality of the interaction between the user and the information systems artefact. While accepting the important contribution of this grand programme to our collective understanding of how people think and act in the 
world, it is important to note that this perspective, like any, is open to criticism, and has its blindness.

There are a number of grounds for being concerned with this grand vision. One line of argument focuses on the groundedness of certain of the concepts that seem to form the very stuff of these accounts. The "cognitive representationalist" conceptualisation of the human has begun to be queried, both for its adequacy and completeness (Winograd and Flores, 1986, Suchman, 1987, Bannon, 1990). Other sets of concepts have been suggested that might provide a better coupling between human action and the experienced world. These accounts problematise such basic notions as "problem", “information", “decision", "plan”, "representation", "goal”, etc. and argue that such concepts may not bear much relation to the everyday mundane realities of how people think and act in the world. As a powerful example of an alternative approach, Winograd and Flores (1986) provide a radical critique of the Western intellectual tradition, which they claim is based on a limited concept of rationality that underlies the majority of the work undertaken in management information systems. The certainties of basic concepts in the field are problematised and re-interpreted by others, relying on a hermeneutic and phenomenological position (e.g. Boland, 1985, 1987, Preston, 1991). The emphasis on quantitative models gives way to an examination of the qualities of accounts, description gives way to interpretation. Such approaches argue for a radical overhaul of our accepted ideas on the appropriate ontologies and epistemologies for studying the computer support of human and organisational action.

At another level, the accepted framework has been criticised on pragmatic grounds, in that practitioners claim that their experience does not fit with the models and expectations of the researchers. Many empirical studies have shown that people make decisions in organisations - or perhaps it might be more correct to say that decisions simply get made in organisations - due to a variety of reasons that are poorly accommodated within the standard model of ratiocinative behaviour. The accepted view that managers constantly seek additional information in order to improve the quality of their decisions has been discounted by empirical evidence. Indeed it appears that often the reverse is the case, they try to reduce the amount of information that is to be considered. Whether or not the view of managers as "decision-makers" is even appropriate is targeted by some: for example, Mintzberg has noted how people do many things besides making decisions in their work, and March (1991) notes: "Decision makers often operate in a surveillance mode rather than a problem-solving mode...they characteristically do not "solve" problems; they apply rules and copy solutions from others." Perhaps "decision" is not the most appropriate concept upon which to develop a theory of support. The awareness of motives and politics in the construction and use of "information" is also neglected in this perspective on DSS, and in MIS more generally. As Keen (1981) noted, some time ago: "Information is only a small component of organisational decision processes; human information-processing is experiential and relies on 
simplification, organisations are complex ..... Data is not merely an intellectual commodity but a political resource, whose redistribution through new information systems affects the interests of particular members. "It should be noted that such challenges to the accepted position have been proffered over the years by a variety of scholars, including from certain quarters within the MIS/DSS area itself . For example, from an early stage, Huber (1980) has noted the limited applicability of the standard model and pointed to the need for alternative decision models. The later work of March himself adds to the critique. Member of the Irvine group - Rob Kling, John King, Ken Kraemer and others - have contributed both conceptually and empirically to a somewhat different account of how people act in organisations, and the way computer-based systems can be appropriated for a variety of ends. Also, in a paper only recently brought to my attention, Jones (1994) notes similar critiques of the rationalist position in the context of GDSSs.

In sum, in recent years we have seen an attack on the accepted position of managers as primarily decision makers, based on both conceptual and empirical grounds. The studies paradigmatic of the decision making genre, involving experimental laboratory studies, using students as subjects, has been exposed as of little relevance to what happens when decisions occur in organisations. The neutral conception of topics such as "information" has been demolished. There is a concern about the social and organisational aspects of decision making and technology support, which go beyond sterile conceptions of "context" as an additional variable that needs to be added to our existing models. The limitations of the models we build and use need to be recognised. There is an interest in allowing for richer forms of interpretation of how people function in organisations, and of how actions are taken. The information processing view of how people function is being enriched, if not replaced, by a range of perspectives such as symbolic interactionism, ethnomethodology, cultural-historical theory, phenomenology, which require us to re-examine the ontologies and epistemologies espoused in traditional material. However, this paper is not so much a simple critique of DSS as it is a view on certain group decision support systems (GDSSs) and the assumptions they embody, to which we now turn.

\section{INVESTIGATING GDSS}

"The field of GDSSs is as yet not well developed, even as a concept. There are divergent and conflicting definitions of what the term means....moreover, even the simple technologies of GDSSs have had only limited adoption and use in organisations."

\section{Kraemer and King (1988)}

Group decision support systems (GDSSs) can be seen as DSSs that have been augmented by the fact that there is more than one decision maker involved, and so some computer support for communication and the integration of multiple inputs 
is provided. The interest in GDSS stems in part from the rise of interest in the area of technological support for groups, which can be seen in a variety of other research areas - for example human-computer interaction and organisational design - in recent years. While there are a variety of different kinds of GDSS systems around, both experimental and commercial, our focus here will be on a class of systems generically referred to as Electronic Meeting Systems (EMSs) or computeraugmented meeting rooms. Such systems have received a lot of attention of late, in both the information systems and the organisational literature. They can be characterised as comprising three components - a physical setting, a set of computer-based tools, and a meeting facilitator who moderates the meeting, and supports the group in their use of the tools. The settings can range from the very specialised - such as the early rooms configured for the University of Arizona work, and the original POD (marketed by ICL, Lucas Interiors, and AudioVisual Material Ltd.) - which can cost many thousands of pounds to equip with special workstations, computers and group displays, configured work surfaces, modifiable lighting, etc. through to ordinary meeting rooms, where portable PCs can be setup on a local area network in minutes and be ready for use. The tools usually include some support for different phases of group activity, such as idea generation and selection, and various decision models. While some GDSSs can be used by the group on a "stand-alone" basis, in a number of cases they require a meeting facilitator who acts as a chauffeur for the group, helping the group in the development of the meeting agenda, and in the use of appropriate tools for the groups activities. Some well known systems include the University of Minnesota SAMM system, the Capture Lab in Michigan, the University of Arizona spin-offs GroupSystems marketed by Ventana, as well as the version called TeamFocus by IBM, and VisionQuest marketed by Collaborative Technologies Corporation.

Much published GDSS work that I have come across perseveres with the accepted rational cognitive model of decision making activity previously described in this paper, with a concern for understanding the decision making process, basically still individual cognition, but with the proviso that now there are multiple people - a group - that is involved in the decision, so there must be some attention to "group process". As an exemplar of this approach, for further discussion, I will refer to the work of Jay Nunamaker and his colleagues at the University of Arizona, who have been involved in the development of GDSSs for a number of years. Out of this work initially came the software tool PLEXSYS, then the commercial system GroupSystems V, sold by Ventana Corp., and a related system marketed by IBM known as TeamFocus. The system consists of a number of different tools that are intended to assist in aspects of the group decision-making process. These tools have evolved over the years as a result of experiences of use. There is support for brainstorming activity, for ranking alternative choices and voting on them, for preserving anonymity, etc. Focus has been on the support of co-located real-time teams, but the technology can be adapted for use in remote situations or for non-real-time use. There have been numerous studies conducted on 
the system, both in the laboratory and, more recently, field settings. The work of this group has been documented extensively in a plethora of reports, theses, and conferences and journals in the areas of MIS, DSS, and CSCW. For an overview of this work, see Nunamaker, Dennis, Valacich, Vogel, and George (1991). Indeed part of the reason why this work will form the basis for discussion is precisely because it is so well-known and available ${ }^{2}$. First let us note some of the claims made for the system, and the framework within which is was developed and analysed. Some of the major advantages of the system claimed by the developers are the following:

- people work on the system in parallel, so it is possible to get a lot more ideas into circulation and captured quickly using the system during brainstorming

- since the input is anonymous, there is equal opportunity for participation by all at the meeting, unencumbered with power or status differentials

- the system purportedly enables larger group meetings to be effective through control of the process

- the system permits the group to choose between a variety of techniques

- the system offers access to external information sources so that can be utilised in the group decision process more easily and effectively

- the system supports development of an organisational memory, by keeping a record of the inputs of the participants during the meeting, and of the choices made.

- use of the system in a number of organisations have lead to significant productivity gains based on much shorter lead times for getting decisions made in large groups through use of the system.

We will examine some of these claims later in the paper. The conceptual framework which is used by the University of Arizona research group to support their claims is based on a model that comprises four major factors that are seen as contingently involved in the use of EMSs - these are labelled group, task, context and technology factors. Thus group factors include such issues as size, proximity, composition, cohesiveness etc. Task factors involve the nature of the particular task - brainstorming, decision making, complexity etc. Context factors include such things as - organisational culture, time pressures, evaluative tone of meeting, and the reward structure. Obviously different kinds of technology, and the quality of the interfaces, the familiarity of the technology to the meeting participants, etc., will also have some effect on the meeting process and outcomes. Also, the research framework identifies a set of four conceptual mechanisms by which one can analyse meetings. These are, briefly:

$2 \quad$ My own direct experience with the system involves demonstrations and trials. I have experienced a number of the tools available, and have had discussions with a number of people who have used the system, including, importantly, one of the facilitators for meetings using this system. 
- Process Support - focusing on the communication infrastructure and its support for such features as parallel communication, group memory, anonymity;

- Process Structure - focusing on the rules that direct patterns of activity, e.g. by providing agendas for meetings, or implementing specific forms of turn taking protocols;

- Task support - refers to the information and computational infrastructure that supports the accomplishment of the actual task, e.g. - external databases, spreadsheets, organisational memory elements.

- Task structure - refers to the techniques, rules, and models available to the group for analysing task-related information, akin to the DSS models used by individual decision makers.

It is within this espoused framework that Nunamaker and his research group discuss EMSs, and perform experiments to tease out the contributions of certain identified factors to the overall effectiveness of the group decision making process. Since this approach and exemplars of studies that utilise it, and summaries of the body of work completed to date are widely available, I will not take the time here to describe in further detail this rationale or the empirical studies, but will instead move directly on to a critique of some of the underlying assumptions of this approach, of its methodology, and of its interpretation of the results of its empirical studies. Once again, I accept that there are other approaches to (G)DSS that differ from this paradigm, but I wish to critique it here due to its visibility within the MIS and CSCW communities, where it is viewed, rightly or wrongly, as prototypical of GDSS. This is then followed by a Section that outlines how current work discussed within the CSCW community, while not answering these criticisms, might provide researchers in GDSS with other lenses with which to view the work.

\section{A CRITIQUE OF CERTAIN GDSS ASSUMPTIONS}

First of all, it is important to note that, even within the GDSS field, there is no uniformity of opinion as to what is the best approach to the development and use of GDSSs $^{3}$ - for some discussion, see the articles in Stohr and Konsynski (1992). What has been described above is however a prototypical example of work in the field that has received widespread exposure and so is a legitimate target for critique. The critique focuses on several distinct aspects of the approach, but emphasises the

For example, the work of John King and his colleagues at UC Irvine embodies a perspective on issues in GDSS distinct from much of the prototypical MIS work, and indeed more akin to CSCW work discussed later in the paper. 
over-reliance on the rational model of decision making that has been critiqued earlier and on the nature and use of the group concept in GDSS. Since some of the general critique of this model as being the only or the most appropriate model by which to understand human decision making behaviour has already been presented, comments here will emphasise additional concerns when discussing "group" decisions.

As Whitaker $(1992,1994)$ has cogently argued, much of the work in GDSS has focused on "collecting unit elements, organising and arranging these units, and voting or ranking them"4. Such activities do not circumscribe the range of activities that are important at meetings. Specifically, they ignore or relegate to minor importance such crucial aspects of the meeting process as the initial environmental collation of information, generation of options and concurrent initial interpretation phase, which serves as the very basis or context for all subsequent activities. There is a large body of work from a number of systems perspectives that would consider GDSS as consisting of four major stages, viz. 1) Recognition of a need or problem; 2) Generation of evaluative context; 3) Evaluation of actions and consequences; 4) Selection of action. Whitaker and many others (e.g. Jones, 1994, Humphreys and Nappelbaum, 1997) point out that many current GDSSs ignore stage 1 , and much of stage 2 , focusing on stages 3 and 4 . There is too much focus on the selection stage, and insufficient time given to understanding the context of the different options. The consequences of this approach are serious. Since there is no room for discussion amongst the participants of the grounds on which information is deemed relevant to the task at hand, this model implicitly imposes a set of normative assumptions on the nature of the meeting process. Again, if I may refer directly to Whitaker, who has I believe presented this argument most starkly, the implications of this approach are the following:

- all parties to the decision process are operating with respect to a presumably common ontological foundation

- all parties are capable of submitting ontologically comparable unit options for consideration

- all parties are capable of manipulating these ontologically comparable unit options under conditions of epistemological equivalence during consideration.

- all parties are capable of conducting their epistemological equivalent data manipulations under conditions of uniform rationality."(Whitaker, 1992:36).

Both Whitaker and I would dispute the veracity of these assumptions for the majority of meetings. A simple aggregation and selection of options may be defensible where collaborators are uniformly knowledgeable on the background to the problem, issues, etc. at hand, but is unlikely to be sufficient in cases where we are dealing with actors having differential knowledge, for example, in dealing with

I make extensive use of the thesis work of Randall Whitaker in this paper because I believe that it provides a sustained and effective critique of such GDSS systems. 
multidisciplinary teams or indeed, the majority of situations, where a crucial component of the meeting should involve dialogue and discussion about the nature of the events to be debated and decided on, what counts as evidence, etc.. In these cases, formulating the very task itself may form an essential aspect of the meeting. It is in the "support" of such aspects of meetings that many current GDSSs fall down. At the same time, I am aware that there is a body of work on problem structuring methods which do attempt to support these early stages of group activities, e.g. Eden's (1989) SODA methodology concerning cognitive mapping, the work of Dick Boland and his colleagues (1992) on systems to represent different participant's perspectives, even Checkland's Soft Systems Methodology (1984), but these do not appear to have been taken up by many in the GDSS field. In the remaining part of this section, I investigate a number of problems thus encountered by current GDSSs, including the problem of disparate and discrete ontologies among meeting participants, the politics of decision making and meetings, the importance of talk, dialogue, or conversation in the meeting process, followed by a number of other criticisms that have been voiced about these systems.

\section{a) the problem of different ontologies}

As noted by a number of commentators, the work of meetings is often not simply about making decisions about items on the agenda, but ascertaining whether the language used to describe topics is held in common among the members of the group at the meeting. What one person means by a term of phrase is commonly found not to be the same as what others might mean by the same term or phrase.

The problem is often either pushed under the carpet by the assumption of shared views on the part of the meeting convenor, or else an attempt is made to reconcile possible differences through the establishment of some form of prescribed common dictionary of concepts that all must follow. This latter approach has its difficulties, as has been enumerated in a number of papers (Robinson and Bannon, 1991, Schmidt,1991, Davenport, 1994). While Robinson and Bannon were looking at the problems of "ontological drift" as designs move between groups during the systems development process, the underlying issues we raise in that paper are fundamental to the point under discussion here, as already noted by Whitaker in his GDSS critique. In our paper, we comment that :

"Different groups, professions, and subcultures embody different perspectives. They communicate in different "jargon". Much of this cannot be translated in a satisfactory way into terms used by other groups, since it reflects a different way of acting in the world (a different ontology and epistemology). Distinct groups of this sort will be referred to as semantic communities. The problem is not resolved by promoting the necessity of open communication -- since this assumes the different groups can be framed in a single semantic world. The meaning of terms is not transparent across groups.. (Robinson and Bannon, 1991)

Schmidt (1991) cites Savage (1987) on a similar point: "...each functional department has its own set of meanings for key terms....Key terms such as part, 
project, subassembly, tolerance are understood differently in different parts of the company" (Savage, 1987). Likewise, Davenport (1994) notes: "No matter how simple or basic a unit of information may seem, there can be valid disagreements about its meaning" and provides several examples from the business world. In such a situation the task of the group in a decision process is not simply "getting it right", as there may be no clear "right" answer. Rather the group must come to some accommodation about the differing world views of the participants, and about the adequacy of the models they employ in their decision process. As Gerson and Star (1986) note: "No representation ..... is either complete or permanent. Rather any description is a snapshot of historical processes in which differing viewpoints, local contingencies and multiple interests have been temporarily reconciled." Many current GDSS systems do not address this fundamental issue, or else handle it in a rather superficial way. Yet there is increasing evidence that the handling of this issue is crucial in terms of meeting outcomes (cf. Jones, 1994).

\section{b) incorporating a political perspective}

The MIS and DSS literature is replete with discussions of conceptual frameworks and resulting software applications that fail in use due to the lack of attention paid to "political" aspects of the problem under study. Too often, the assumption is made that information is a neutral concept. As March (1991) notes: "Most information is subject to strategic misrepresentation or unconscious bias". Such observations assume special importance when we come to discuss the "sharing" of information for the purpose of discussion and decision-making. Apart from the difficulties adumbrated above concerning the potentially different and divisive ontologies of the actors who produce and use the information, information is a strategic resource that will be jealously guarded by owner-actors and used in carefully circumscribed ways at meetings. The failure to take into account the political perspective creates many problems for the utilisation of information and information technology among certain groups. ${ }^{5}$ In the area of EMSs, Grudin (1989) describes how a particular GDSS - gIBIS - which was being used by a group to provide a group memory representing arguments for and against certain design decisions was thrown out by the manager of the group, who was afraid that such an instantiation and reification of the disagreements within his group might be used inappropriately by others in the organisation! Similarly, Lyytinen et al. (1994) in their analysis of diplomatic meeting protocols, note how at many junctures in this complex process the archival properties of a GDSS would preclude its actual use!

As Jones (1994) notes:" it may be argued that conflict is endemic to organisations and that such 'political' use of IT is therefore likely to be more widespread than is often assumed, as Langley (1989) describes." based on her field experiences involving the deployment and use of a DSS. 


\section{c) the importance of talk}

One of the surprising features of a number of the available GDSSs is their lack of support for conversations among the group ${ }^{6}$. Whereas certain views on what meetings are about would give primacy to such discussions among participants, this does not seem to be the case from the (G)DSS perspective. In some cases, group discussion tends to be tightly controlled and orchestrated by the facilitator, who tries to re-focus attention on individual member's tasks at their workstation. In such cases, participants at the meeting report a feeling of dissociation from others, due to the lack of interaction allowed at the meeting. As Whitaker notes, the group are "co-located, yet remote"(Whitaker, 1994). A recent report (Docherty, 1992) documents these concerns. Members of the group experienced their use of the system as constraining: they felt that the system had too heavy an emphasis on hierarchically-organised meetings with the facilitator in control, where there were constraints on interpersonal communication caused by the temptation to focus on the individual workstation, thus leading to a rather impersonal setting where people felt they were acting individually. They also felt that the exclusion of nonsymbolic aspects of communication reduced the effectiveness of the meeting.

Alternatively, the group discussion that does take place happens completely outside the information technology. GDSSs neither support the discussions about the topics entered into the system, nor do they provide any record of any such discussions that may have gone on around the material on the screens. For instance, in an interesting analysis of meeting support system failures in real-world contexts, De Vreede and Muller (1997) note that one of their groups felt that "the group support system (GSS) [GroupSystems] did not enable them to discuss issues, only to put them on the table."(p.1281). They also note how some groups felt uncomfortable communicating via GroupSystems, to such an extent that the group regularly "pushed the keyboards aside and started discussing issues orally"( $p .1278)$ In another example, (Whitaker, 1992) recounts how when the members of the group "broke ranks" and spoke to each other about how to co-ordinate their activities though the system only the results of the decision went into the group memory - the argumentation and discussion about the topic was not captured or marked in any way in the GDSS. This resulted in the situation that much in the way of background context for the decisions taken by the group, the efforts at sense making and attempts to come to a common understanding of the items depicted in the system, were not preserved in the system, and thus not available to others who might wish to review this meeting process at a later date. This poses the question of exactly to what extent do these supposed group support systems actually support the work of the group.

Reflecting on the situation, there appears to be an assumption that too much time at meetings is taken up by "idle talk", and that the preparation of an agenda

$6 \quad$ Indeed at least one early version of the University of Minnesota SAMM GDSS was so constructed that participants at the same co-located meeting using computers were actually seated back-to-back! 
and the pacing of the meeting via the facilitator and software tools will improve effectiveness. I will come back to this issue of efficiency and effectiveness of meetings qua meetings below, but would like to dwell briefly on this apparent disregard for conversation or talk in meetings. If we believe that meetings are a place where different social worlds interact and attempt to understand each others' perspectives on problems, then it would appear that more rather than less emphasis should be given to supporting conversation between members of the group. To reduce oral communication to textual messages on screens does not on the face of it appear to be a way of enhancing group process. As Whitaker (1991) notes: "...the very sort of dialogue current GDSS overlook or relegate to external channels is the very element introduced in shifting information technology support from individual decision makers(DSS) to groups (GDSS)". There appears to be an assumption that what conversation -talk - consists of is simply a series of messages by one person followed by responses from another. Such a view of conversation is known to be far from accurate ${ }^{7}$. Due to the work of conversation analysts and others, we have become aware of the richly nuanced ways in which speaker and hearer "co-produce" their utterances. Making sense of each other is not given a priori. This is admirably described in the following quote from McDermott, Gospodinoff, and Aron (1978). "In addition to sharing knowledge about each other, and whatever it is they are doing together, actors .... struggle to make sense of each other and do work to help generate the kinds of recognisable contexts for common sense to be achieved from one moment to the next. As Garfinkel has pointed out often, the problem facing people in interaction is never simply one of shared knowledge or overlapping interpretive grids. No matter how much people know in common, they must still work at constructing the environments that their mutual knowledge leads them to expect, and any relaxation of this effort can have disastrous consequences. People never know exactly how to make sense of each other.

Recent empirical studies confirm the importance of conversation and communication in the group meeting and decision-making process (Jones, 1994, De Vreede and Muller, 1997).

\section{d) examine the nature of "groups"}

The 'group' concept in GDSS is problematic on a number of grounds. Firstly, there is little consistency in the meaning of the term among research groups and practitioners. In some cases, it would appear that groups are characterised by a number of specific properties, for example, that all members are homogeneous, of equal status, engage in frequent face-to-face contact, share a common goal, etc. Yet others seem to use the term for any agglomeration of people - for example, in his book on Groupware, Johansen (1988) mentions "teams, projects, meetings,

7 Indeed, failure to take this into account was shown to be a prime cause of problems for one group support system - Xerox PARC's CoLab(Tatar et al, 1991). 
committees, task forces" etc. as examples of "groups" and even includes interaction among workers, supervisors and management in manufacturing operations, "often across both distances and work shifts", under the same notion. Secondly, even on the rare occasions when real world groups are investigated, there is an emphasis on studying small, integrated, focused teams, with a well specified shared goal, which again is hardly representative of the way people work collectively in many settings. As Lyytinen et al. (1994) note:

"---the conception of a small cohesive team with fixed participants, a clear task, and shared goals is not necessarily appropriate in informing the design and examination of all EMS systems. Groups are not always small, their participants come and go, their goals are neither shared nor existing, and their tasks can be ambiguous, and under constant shift and drift."

Investigating actual work situations, we discover that there are a variety of ways in which people work together, but that many of them do not conform to any of the images of "group" work. We certainly do not want to restrict the scope of GDSSs to those cases where the responsibility of performing a task has been allocated to or assumed by a relatively closed and fixed collective. This would lead us to ignore or even dismiss the major challenges posed by the design of systems that support co-operative work arrangements that are characterised by a large and maybe indeterminate number of participants, differing conceptualisations, incompatible strategies, conflicting goals and motives, etc.

\section{e) critiquing GDSS empirical research methodologies}

While a large number of empirical studies are cited by GDSS researchers in support of their claims, many of them need to be treated with caution, due to a number of limitations of the published studies. Much of this research is overly technologyoriented and exhibits a relatively narrow conception of 'meetings'. Critiques of the studies come from those within the DSS community as well as outside. For example, a recent (G)DSS review book accepts that the majority of published DSS studies have been laboratory bound often with students as subjects and argue that: "We must begin to study real people in real settings working on real tasks"(Elam et al., 1992:69). In sum, they comment, and I would agree strongly:

"Specific laboratory studies have been criticised because they use student groups and artificial tasks rather than ongoing groups that have decisions to make that are of importance to the group; they usually involve only a single meeting; they assume that the particular GDSS and experimental situation are representative and can be used to draw conclusions about all GDSS; they focus on changes in outcomes and individual satisfaction, but not on changes in group process or group dynamics, and they differ only slightly, typically in one or two variables being set at different levels, from previous experiments." (Gray et al., 1992:83)

While some of these problems are being tackled in more recent GDSS work, much of this criticism remains valid. 


\section{f) a critique of efficiency/effectiveness claims}

As noted earlier, some of the claimed benefits of GDSSs are that they decrease the time spent on meetings significantly, and lead to greater satisfaction on the part of the group members. It can be difficult to assess the validity of these claims, as often the comparison is made between "time taken to reach a decision with the system" versus "people's estimate of how long it would take to make the decision without the specific technology". Such estimations are difficult to validate. Also there are questions about how to measure the quality of a meeting, from whose perspective, and to the commitment of the participants to the decisions reached in the meeting, as the meeting is but part of an organisational process to implement the decisions reached. Measuring such aspects is a difficult process.

Much has been made of the increased efficiency of groups using meeting systems through the ability to each group member to input ideas in parallel via the computer system, rather than turn-taking in a face-to-face meting situation. There area number of issues that are need to be mentioned here. Firstly, the very idea that this sort of parallel brainstorming is effective, in the sense that it produces (collectively) better ideas is dubious (Cf. Hoffman, 1978, cited in Whitaker, 1992). Secondly, the focus of these measures is in terms of quantitative units of ideas produced, with little focus on the qualitative dimensions of the concepts. A number of empirical studies have noted this problem. De Vreede and Muller (1994) note that the participants themselves focused on the number of ideas that served the meeting goals, not simply the number of ideas generated. Thirdly, the dialogue directed toward analysing or critiquing the atomic "ideas" themselves remains outside the shared information space that is produced: "In GroupSystems, brainstorming is performed by a group but not as a group" (Whitaker, 1992). Granted, this method does produce a lot of material, but then again, there is a tradeoff between the individual production of text and the time taken to read and evaluate it all by the whole group, as described in Docherty (1992).

More generally, there is the question of what kinds of meeting are such systems appropriate for? In situations where the group agrees on the general framework of important factors in the decision-making process, then the system may speed up the process, but in situations where the major topic of the meeting is arguing about the very grounds for making the decision, it does not seem that the rather simple model of decision-making embodied in these systems would be appropriate. While not denying that the use of GDSSs can have positive outcomes, I believe that there is a need to examine some of the claims carefully, in order to understand what exactly is going on. Once again, there does seem to be an emphasis on certain quantitative measures, without sufficient explication of what exactly such measures might mean. As noted by Lyytinen et al. (1994), reduction in meeting time is often too simplistic an output measure. Indeed, depending on the kind of meeting, they comment how it may be the way in which the "idle time" between meetings is managed by the meeting organisers that can significantly affect the final meeting outcome, rather than what happens in the meeting per se. 


\section{g) the relevance of anonymity}

Again, the claims made for the benefits of anonymity with electronic meeting systems need qualification, especially as this feature is so often highlighted as a key feature of certain GDSSs. While undoubtedly there are cases where there are benefits, it is also the case that there are many exceptions. Reduced user identity can be dysfunctional in certain settings, as noted in a number of empirical studies. For example, De Vreede and Muller (1997) note: "Participants appeared to find anonymous discussing to be too impersonal, too sterile.....anonymity was sometimes considered to harm the quality of information exchange" (p.1276). Lyytinen et al. (1994) also raise this concern. In many situations, it is crucial to know who says what, as not all members at the meeting are perceived as equally competent. Anonymity is also counterproductive in situations where specific individuals are necessarily linked to given positions or where the goal is "sharing personal perspectives" between the group members. Much closer scrutiny needs to be paid to this whole issue, as certainly general statements as to the benefits of anonymity seem increasingly dubious in the light of recent studies.

\section{WHAT'S NEW IN CSCW?}

Having now explored some of the claims of certain work in the (G)DSS area, and noted some problems with the work to date, I wish to turn my attention to CSCW and see to what extent this field may be of interest to GDSS, and why. My purpose is not to give an overview of the field here, as I have done this elsewhere (Bannon, 1993), but to focus on issues and aspects of CSCW that are relevant to the concerns expressed already in this paper. After a short introduction, I focus on a few key features of work in CSCW that may be of interest to the GDSS area, before discussing some possible lines of co-operation between the communities in the concluding section.

The term "Computer Supported Cooperative Work" (CSCW) has come to embrace a variety of research in such overlapping areas as workgroup computing, collaborative computing, groupware, co-ordination technology, augmented business teams, group decision support systems, and co-operative work support. Some of the key features of this agglomeration of terms, as distinct say from more general fields such as management information systems, or human - computer interaction, is an interest in supporting groups or ensembles, rather than individuals or whole organisations, with information technology. CSCW entails both a wider remit than traditional information systems as regards the different settings in which it is appropriate to study co-operative work arrangements, as well as a more explicit focus on the "support requirements" of co-operative work and the way people create, manage, disable, modify, etc. computer-based mechanisms of interaction than is seen in the other fields. Studies in such diverse areas as computer-aided design (CAD), computer-integrated manufacturing (CIM), computer-aided software 
engineering (CASE), group decision support systems (GDSS) etc., are all relevant to the CSCW field to the extent that they study the use of computers to support cooperative work in different domains. A focus on the multiplicity and complexity of co-operative work arrangements and problems and prospects for their computer augmentation is what some would regard as what is "new" in the field. For others, CSCW is more a paradigm shift in the way we perceive how work is accomplished, one that focuses on the sociality of work and the consequences of taking this notion seriously in designing computer support.

So, how does this relate to the (G)DSS field described above? In a recent (G)DSS book, the authors note: "Obviously, CSCW intersects with GDSS. CSCW focuses on the use of computer-based connectivity to support co-ordination and collaboration of knowledge workers and to enhance efficiency and effectiveness of knowledge work processes in general. On the other hard, GDSS tends to focus on processes that lead to management decisions. " (Stohr, Konsynski, and McGee, 1992:20). So, on this view, GDSS is a subset of the more embracing CSCW field. The fact that papers on (G)DSS have appeared in CSCW conferences supports the notion that the two fields are closely interlinked. Despite this apparent overlap of fields however, I would urge some caution, as I do not believe that the GDSS studies and systems that I have described above share the same set of concerns evident among many in the CSCW community concerning the nature of work in organisations. The point here is not that one perspective is necessarily more "correct", but rather to point out that much of the literature that appears under the rubric of GDSS stems from a different tradition and different practices to the work in CSCW. In this section I will outline some features of the "new" field that I believe are distinct.

First of all it is important to note that, just like in (G)DSS, there is no single view of the nature of the CSCW field. I have elsewhere described a number of different viewpoints that can be found in the literature, from simply viewing CSCW as "software for groups", to seeing it as a new paradigm for the building of information systems in general that pays attention to the socially organised character of work activities (see Bannon, 1993). Another view focuses more specifically on co-operative work as a distinct category of work, and investigates the features of co-operative work forms, focusing on the ways in which people cooperate, and the mechanisms of interaction that have evolved (Schmidt, 1990, Bannon and Schmidt, 1991, Schmidt and Bannon, 1992). It is an interdisciplinary community, embracing the software and social sciences. One of the important contributions of CSCW work has been the detailed investigation of exactly how work gets done in organisations, with a particular focus on co-operation, coordination and communication in work. An influential voice in this community is that of ethnographers, who have raised the awareness of systems designers to the problems caused by information systems constructed according to simplified models of work activities. These researchers have pointed to the need for detailed studies of the circumstances in which work is conducted, at all levels in the organisation, 
from the factory floor to the executive boardroom. Office room talk is subject to the same scrutiny as management "decision-making" activities. This is one area where I believe the work in CSCW may be of interest to (G)DSS. The CSCW work highlights a number of important features of real world co-operative work, including the following (Bannon and Schmidt, 1991, Schmidt and Bannon, 1992):

- co-operative work involves far more than what is commonly seen as group work

- co-operative work requires articulation work as well as task-oriented work

- co-operative work may occur even in the absence of explicit communication between parties

- decision making is often distributed and discretionary, requiring mechanisms to handle the reconciliation of different conceptualisations and heuristics used by the ensemble of co-ordinating actors.

In the material following, I have highlighted some of the areas where I feel the approaches and insights expressed in the CSCW arena may be of particular interest to the GDSS community.

\section{a) The role of models: from depicting to reframing}

While early CSCW work focused on the modelling of human roles and activities, and human communication patterns, there has been a growing realisation that the standard ways of viewing such activities and behaviours has suffered from too narrow a view of how people act in the world. There has developed a new awareness of the role of models in systems development, away from a prescriptive stance. A view of modelling that sees it merely as a description of an accepted reality, or an abstraction of it, can lead to serious difficulties. Accepting that there is a sense in which all description is really interpretation (Geertz, 1973) causes us to be more careful in ascribing veridicality to our models. In an earlier paper by Mike Robinson and myself, we have described some of the problems found when people model:

- There is a constant temptation for designers to confuse the models with an underlying reality.

- The models impose an ordering on people and or events, often unilaterally.

- The models are difficult for "users" to understand and thus

- preclude people from appropriating and re-working the model in situations of use.

- The models do not define their basic concepts adequately.

- Emphasis appears to be on model form and elegance over actual coverage and practicality or usefulness.

- Emphasis is on "determinism" at the expense of "interpretation" in work processes. 
- The models embody an inappropriate correspondence theory of truth, and thus make the untenable assumption of a specifiable, one-to-one, decontextualized relationship between an instruction and the action that satisfies it. (Robinson and Bannon, 1991).

Much work in CSCW has come to re-appraise the role of models, and has begun to pay attention to ways in which people use these models as guides for behaviour, rather than as prescriptions. "Models are then seen as interpretations, as constructions, which for some purposes, under certain conditions, used by certain people, in certain situations may be found useful, not true or false. We thus see the modelling process as one of reframing rather than describing or abstracting". (Robinson and Bannon, 1991). While the thrust of our remarks were oriented to people doing office or work modelling, the implications of such views for work in (G)DSS - and indeed, CSCW itself - need to be examined in greater detail.

\section{b) more distributed, less group, decision-making}

As we noted earlier, it has - implicitly or explicitly - been the underlying assumption in most of the (G)DSS and CSCW-oriented research thus far that the cooperative work arrangement to be supported by a computer artefact is a small, stable, egalitarian, homogeneous, and harmonious ensemble of people, - a 'group'. But if we investigate actual work situations, the privileged status of the "group" concept quickly dissolves. Other factors come into play, if we are to understand how work gets accomplished, and what kind of computer support is required. As Schmidt and Bannon (1991: 15) note:

- Cooperative ensembles are either large, or they are embedded within larger ensembles.

- Cooperative ensembles are often transient formations, emerging to handle a particular situation after which they dissolve again.

- Membership of cooperative ensembles is not stable and often even nondeterminable. Cooperative ensembles typically intersect.

- The pattern of interaction in cooperative work changes dynamically with the requirements and constraints of the situation.

- Cooperative work is distributed physically, in time and space.

- Cooperative work is distributed logically, in terms of control, in the sense that agents are semi-autonomous in their partial work. Cooperative work involves incommensurate perspectives (professions, specialities, work functions, responsibilities) as well as incongruent strategies and discordant motives.

- There are no omniscient agents in cooperative work in natural settings.

Since there is no omniscient agent in many of these situations, decision making is inevitably distributed among the decision making agents, who have unique situations to face, and their own sets of perspectives, goals, interests to take into 
account. As Boland et al. (1992) describe it: "Distributed decision making involves a set of actors who are autonomous within their sphere of concern, and who act independently based upon their own understanding of the situation they confront, but who recognise that they have interdependencies among themselves." The cooperative process of decision making in such situations is a very differentiated process involving the interaction of multiple goals of different scope and nature as well as different heuristics, conceptual frameworks, etc. (see Schmidt, 1990). Much GDSS work pays relatively scant attention to handling such issues, and the broadening of the scope of classic GDSSs to handle them might be informative.

\section{c) Aspects of Information}

Within CSCW, there has developed an awareness of the nuances of the concept of "information" in organizational life. Information is not seen as some neutral concept, but as one with political and contextual connotations. Indeed, Kjeld Schmidt and I have outlined how it is important to understand the source of information, the context in which information is produced and the politics of information production and use in some detail elsewhere (Schmidt and Bannon, 1992). Suffice it to say here that the consequences of such a perspective for information system development are serious, and raise a lot of questions as to the generally accepted view of information as discrete, factual and non-negotiable. On this latter point, especially in the context of distributed decision-making, it is imperative that the origins of the information are known to all concerned, in order to allow the exercise of mutual critique of the decisions arrived at by colleagues, in that different people may use different problem-solving strategies. Others involved in the distributed decision-making may wish to ascertain this background information, in order to balance individual biases. Cicourel (1990) illustrates this need powerfully in the context of medical decision-making, noting that "the source of a medical opinion remains a powerful determinant of its influence." That is, "physicians typically assess the adequacy of medical information on the basis of the perceived credibility of the source, whether the source is the patient or another physician." Thus "advice from physicians who are perceived as 'good doctors' is highly valued, whereas advice from sources perceived as less credible may be discounted."(Cicourel, 1990). Relatively little attention to such differences appears to have been paid in the GDSS literature on groups and decision-making that I am familiar with.

In CSCW, attention has shifted away from questions of support for face-to-face meetings and group decision-making towards the development of an understanding of how to support distributed decision-making and cooperative work activities where people are working at "arm's length", without much direct communication and without necessarily even knowing each other or knowing of each other. In such cases, people must cooperate via a more or less shared or common information space, that is, "a 'space' comprising data, personal beliefs, shared concepts, professional heuristics etc."(Bannon and Schmidt, 1991). By ignoring the diversity 
and discord of the 'goals' of the participants involved, the differentiation of strategies, and the incongruence of the conceptual frames of reference within a cooperating ensemble, much of the current GDSS (and indeed CSCW) research evades the problem of how to provide computer support for people co-operating through the establishment of a common information space (Schmidt and Bannon, 1992). In this perspective, shared databases do not guarantee shared interpretations of the data, but actors must locally and severally jointly construct shared meanings for this data, and even when such shared meanings are arrived at, they are still seen as contingent, local, and temporal (cf. Bannon and Bødker, 1997).

\section{d) Work requires articulation}

The importance of articulation work (Strauss, 1985) - the work that is required to be done in order for any division of labour to function smoothly - in understanding how people manage to co-operatively accomplish their work is another insight that has been investigated in some detail in CSCW work (Schmidt and Bannon, 1992). This is of some relevance in the context of our discussion of GDSSs as it points once again to the work that has to be done in order to allow "work" to be done, something that is ignored in many functionalist information systems models.

Building computer systems where the work is seen as simply being concerned with 'information flow,' and neglecting the articulation work needed to make the 'flow' possible, can lead to serious problems. The organisational models embedded in CSCW applications should be treated as resources for competent and capable workers rather than as executable code. That is, the system should make the underlying model accessible to users and, indeed, support users in interpreting the procedure, to evaluate its rationale and implications. It should support users in applying and adapting the model to the situation at hand. The system should even support users in modifying the underlying model and creating new models where appropriate in accordance with the changing organisational realities and needs. The system should also support the documentation and communication of decisions to adapt, circumvent, execute, modify etc. the underlying model.

\section{e) Understanding practices}

There is a body of work in CSCW that pays particular attention to the nature and organisation of everyday work practices and their centrality in the accomplishment of work activities. This increasingly prominent view re-conceptualises the nature of work and organisational life, and the role of information technology support. It emphasises work practices, and the way learning is accomplished within communities of practice. It argues that learning and action are 'situated' (Suchman, 1987), and that work is a complexly social affair, mediated by other people and artefacts. Such a view contrast strongly with a number of common assumptions about work, found in areas such as human engineering, scientific management, and cognitive science, and still underlying many aspects of GDSS. Sachs (1995) argues passionately and cogently for this need to re-conceptualise the nature of work, away from what she terms an "organisational" view, to one she labels 
"activity - oriented". To synopșize these perspectives the organisational view is still the predominant one in organizations today, grounded in scientific management ideas, focusing on training, tasks, procedures, workflow and teams, in contrast to the activity-oriented view focusing on learning, know-how, networks, conceptual understanding, work practices, judgement, and communities (of practice).

The relevance of this perspective to our present discussion is twofold. Firstly, it is yet another voice that is arguing for the need to understand the details of work in situ in order to provide appropriate technology to support it. This has implications for GDSSs, in that the tools they provide need to be developed and tested within ongoing work situations in order to truly assess them, rather than in the lab. Secondly, it suggests the idea of learning over time, in communities. Recently, much attention has been paid to how technologies evolve in use. This concern with the evolution of skills with artefacts focuses our attention on the need to study how people appropriate technology over time, through use, and even creative misuse. As Mackay notes, more generally:" Software does not remain static when it is introduced into an organisation. People in the organisation evolve their individual patterns of use, share them with each other, react to external changes, both technical and non-technical, and sometimes pro-actively modify the system to produce significant innovations." (Mackay, 1990). Thus not only must we embed our systems, of whatever form - including GDSSs - into particular situations, but we should observe how these systems are used by people over time, and how use changes. In my reading of GDSS literature, such issues are rarely to the fore, and yet, while preparing this paper I came across a paper which presented a very similar argument (Poole and DeSanctis, 1989). Briefly, while they frame their remarks within adaptive structuration theory, some of their observations are identical. They note, for instance, "it is use that makes GDSSs what they are in a given context and gives them reality...It is not sufficient to treat the GDSS as a given technology and assume it has determining effects on users. Nor is it sufficient simply to study user attitudes toward and acceptance of the system. The GDSS and users are bound up in an encompassing process that shapes and mediates the GDSS impacts." I would certainly agree with this, and my next question would be to what extent have such ideas influenced GDSS work?

\section{CONCLUDING REMARKS: OPENING UP CONVERSATION BETWEEN GDSS AND CSCW}

The intention of this paper has been to open up a dialogue between two communities which up until now have not cross-fertilised each other to the extent possible, given their stated concerns. I have tried to provide an account, from my own personal perspective, of where I see problems with a certain body of literature and systems which I have encountered to date in the field of (G)DSS, fully acknowledging that this view is certainly selective in scope and that my arguments do not apply to all work in the field. I have shown briefly where I feel that some 
of the concerns of the CSCW community might be of interest and raise debate and discussion on these issues in the (G)DSS community. To my mind, much turns on how one approaches such concepts as "decision-making" in organizations, i.e. whether one narrowly delimits the field of enquiry to a particular category of actions and settings, or whether one accepts that in the end, most work activities, throughout an organization involve sense-making, interpretation, and, yes, on occasions, decision-making. It should be obvious from the foregoing that I am of the latter persuasion, which is why I have included so much material about work activities more generally, because from my perspective, they too are relevant to the discussion at hand.

Clearly, this is only half of the story. I would encourage members of the (G)DSS community to compose the other half of the story, by investigating work in the CSCW field and providing a complementary critique of $\mathrm{CSCW}$ in the context of (G)DSS perspectives. In the meantime, let me conclude this paper with a brief list of some themes or topics that it might be fruitful for the CSCW and GDSS communities to jointly explore and debate:

\section{- Pluralism in conceptual frameworks}

The rational actor model of decision-making is a powerful perspective that has held sway for a long time in a number of fields. Might it not be of interest to investigate how other frameworks view the world of business, management and "decisions"? Such approaches as hermeneutics and phenomenology may re-frame some thorny issues, and allow for new insights and understandings, for both the actors involved, and the researchers (e.g. Preston, 1991).

\section{- Decision-making}

One of the strengths of the ethnomethodological programme that has been visible in CSCW has been its detailed and insightful accounts of how work gets done in organizations, as these accounts include descriptions and interpretations of local problem solving and decision making, as well as accounts of how larger, more formal, meetings are called, conducted and decisions arrived at. It would be a worthwhile exercise to organise a workshop between GDSS researchers, behavioural decision-making researchers and sociological researchers in CSCW to discuss their varied understandings of meeting processes, settings and outcomes. How do we reconcile their at times competing visions of how decisions are made?

\section{- Information Use in Organizations}

We have discussed a variety of issues around the nature and use of information in organizations and its role in decision-making. But the description above presents a rather static view on the concept and role of information in organizational life, that needs to be enriched and melded with other views. Just for example, how do we reconcile the view that good decision making is premised on large quantities of information with the view that managers only collect such information for political 
purposes, in order to show others how well prepared they are? What do we mean by "information" in any case?

\section{- Understanding Groups}

To what extent are groups as traditionally conceptualised, relevant to modern business functioning. Can we reconcile the results of studies done on group process in the lab with what seems to happen within organizations? Might we do better if we understand how decision making is actually occurring in organizations, in a distributed fashion, rather than in some centralised group fashion. Detailed, on the ground, studies would appear to be called for here.

\section{- Communication or Conversation?}

How people interact and manage conversation in meetings is a complex skill, and if technology is to "support" this process it would appear to require richer models of communication embedded in it that is currently the case in some of the (G)DSSs that we have mentioned. As Robinson and Bannon (1991) note: "One particularly exciting area for further research lies in the exploration of "turn taking" and its support in CSCW systems. This complex yet universal aspect of human interaction, resting as it does on a mix of procedures, conventions and moral orders offers an interesting nexus for the concerns of many disciplinary communities within CSCW." - and I might add, GDSS. We also have a wide variety of other conceptual frameworks that could be applied here to enrich our concepts of communication and conversation. For example, the work of Gordon Pask on Conversation Theory, concepts from critical theory - Habermas' theory of communicative action, etc.

\section{- The role of models}

There are many issues that need to be addressed here. What is being modelled? Who constructs the model, who owns it, who can manipulate it, change it etc.? How do people relate to these models, work with them, in them.? What kind of language do we use to describe them, manipulate them, etc.? What role do models play in the support systems we generate? Do we model people in our systems, and if so, how? How do we handle the relation between individual and collective models? Are the models prescriptive or descriptive?

\section{- (Mis-) Use of tools}

Perhaps further investigation of how currently available GDSSs are actually used in practice could help us in understanding how people appropriate tools and also provide new insights for design. Creative misuse, or unanticipated use, can certainly provoke reflection and redesign (Mackay, 1990). I am not aware of much literature on the details of actual use of GDSSs in the material that $I$ have to hand. Certainly, studies of use of (G)DSSs/CSCW systems by members other than the 
design team can produce striking results, as witnessed by the study on the Xerox PARC CoLab (Tatar, Foster and Bobrow, 1991). The pooling of experiences of use by both the CSCW and GDSS communities would be of great interest, as currently, even in CSCW, there is a dearth of such evaluative field studies (Bannon, 1996). The whole role of the support system in the context of the group task and context also needs to be investigated. For example, one of the facilitators who used (G)DSSs extensively confided to me how meetings where the technology played a secondary role, i.e. the focus is on the meeting conversations, with only intermittent use of the "support" technology, tended to be the ones perceived by the group as most satisfactory. So perhaps we need to reduce the emphasis on the structuring aspects of the technology and special-purpose setting throughout the meeting, and investigate its selective use. What this would imply for the whole concept of 'group support systems' is a moot point. Perhaps it would simply take away some of the fascination for large scale technical fixes for what are ultimately social problems, and encourage the development of simpler, more convivial computerised tools that can be picked up and discarded at will by the group participants during their mundane meetings.

\section{ACKNOWLEDGEMENTS}

I would like to thank first my colleagues Kjeld Schmidt and Mike Robinson, with whom I first charted the CSCW waters, and who have influenced my thinking over the years. The work of Rob Kling and John King of Irvine also had an impact from an early period. For the invitation to the IFIP 8.3 meeting that led to this paper, I wish to thank Patrick Humphreys. For useful, occasional, discussions on DSS and MIS, I would like to thank Dian Kjærgaard, Randall Whitaker, and Dick Boland. None of the above should be held responsible for anything that appears in the paper. Initial work on this paper was supported by a contract with the Cognitive Systems Group, Risø National Laboratory, Denmark as part of the Esprit Basic Research Action 6225 (COMIC). Further support from the EU TMR COTCOS Programme is also acknowledged.

\section{REFERENCES}

Bannon, L. (1990) A Pilgrim's Progress: From Cognitive Science to Cooperative Design. AI and Society, 4, 1990, 259-275.

Bannon, L. (1993) CSCW: An Initial Exploration. Scandinavian Journal of Information Systems, August

Bannon, L. (1996) Use, Design, and Evaluation: Steps towards an Integration, in The Design of Computer-Supported Cooperative Work and Groupware Systems (eds. D. Shapiro, M. Tauber and R. Traunmueller) North-Holland, Amsterdam. 
Bannon, L. (1997) Group Decision Support Systems: An Analysis And Critique, in Proceedings of the 5th European Conference on Information Systems, June, Cork, vol. 1, 526-535.

Bannon, L. and Bødker, S. (1997) Constructing Common Information Spaces, in Proceedings ECSCW'97, Lancaster.

Bannon, L. and Schmidt, K. (1991) CSCW: Four Characters in Search of a Context, in Studies in Computer Supported Cooperative Work: Theory, Practice and Design. (eds. J. Bowers and S. Benford) North-Holland, Amsterdam.

Boland, Jr., R. (1985) Phenomenology: A preferred approach to research on information systems, in Research Methods in information systems (eds. E. Mumford, R. Hirschheim, G. Fitzgerald, and A.T. Wood-Harper) NorthHolland, Amsterdam.

Boland, Jr., R. (1987) The in-formation of information systems, in Critical Issues in Information Systems Research (eds. R.J. Boland, Jr., and R. Hirschheim) Wiley, New York.

Boland, Jr., R., Maheshwari, A., Te'eni, D., Schwartz, D., and Tenkasi, (1992) Sharing Perspectives in Distributed Decision Making, in Proceedings of CSCW'92, Computer-Supported Cooperative Work Conference, Toronto (eds. J. Turner and R. Kraut) ACM Press.

Checkland, P. (1984) Systems Thinking, Systems Practice. Wiley, Chichester.

Cicourel, A. V. (1990) The Integration of Distributed Knowledge in Collaborative Medical Diagnosis, in Intellectual Teamwork: Social and Technological Foundations of Cooperative Work (ed. J. Galegher, R. Kraut, and C. Egido,: Lawrence Erlbaum Associates, Hillsdale, N. J.

Davenport, T. (1994). Saving IT's Soul: Human-Centered Information Management. Harvard Business Review, March-April, 119-131.

De Vreede, J. and Muller, P. (1997) Why some meetings just don't work: Exploring success factors of electronic meetings, in Proceedings of the 5th European Conference on Information Systems, vol. 3, pp. 1266-1285.

Eden, C. (1989) Using cognitive mapping for strategic options development and analysis, in Rational Analysis for a Problematic World (ed. J. Rosenhead) Wiley, Chichester.

Elam, J., Jarvenpaa, S. and Schkade, D. (1992) Behavioral Decision Theory and DSS: New Opportunites for Collaborative Research, in Information Systems and Decision Processes (eds. E. Stohr and B. Konsynski) IEEE Computer Society Press, Los Alamitos, California.

Docherty, P. (Ed., 1992) CSCW/Groupware: A Promise soon to be realised? TELDOK Report No. 71, Stockholm.

Geertz, C. (1973) Interpretation of Cultures. Basic Books, New York.

Gerson, E. M. and Star, S. L. (1986) Analyzing due process in the workplace. ACM Transactions on Office Information Systems, 4, 257-270. 
Gray, P, Alter, S., DeSanctis, G., Dickson, G., Johansen, R., Kraemer, K., Olfman, L. and Vogel, D. (1992) Group Decision Support systems, in Information Systems and Decision Processes( eds. E. Stohr and B. Konsynski) IEEE Computer Society Press, Los Alamitos, California.

Grudin, J. (1989) Why groupware applications fail: problems in design and evaluation. Office Technology and People, 4, 245-264.

Hoffman, L. (1978) Group problem solving, in Group Processes (ed. L. Berkowitz) Academic Press, New York.

Huber, G. (1980) Organizational science contributions to the design of decision support systems, in Decision Support Systems: Issues and Challenges (eds. G. Fick and R. Sprague) Pergamon, Oxford.

Humphreys, P.C. and Nappelbaum, E. L. (1997) Structure and communications in the process of organisational change: East European experience and its general relevance. This volume.

Johansen, R. (1988) Groupware: Computer Support for Business Teams. The Free Press, New York.

Jones, M. R. (1994) Information technology for Group Decision Support: Beyond GDSS. Journal of Organizational Computing, 4, 23-40.

Keen, P. (1981) Information Systems and Organizational Change. Communications of the ACM, 24, 24-33.

Kjærgaard, D. (1988) Decision Support and Organizational Learning: A Political Cognitive Framework for Assessing Decision Support Systems. Ph.D. Thesis, Institute of Informatics and Management Accounting, Copenhagen Business School, Denmark.

Kjærgaard, D. (1989) A political-cognitive view of the knowledge-base for management support., in Knowledge based Management Support Systems (eds. G. Doukidis, F. Land and G. Miller) Wiley, Chichester.

Kling, R. (1980) Social Analyses of Computing: Theoretical Perspectives in Recent Empirical Research. Computing Surveys, 12, 61-110.

Konsynski, B. , Stohr, E. and McGee, J. (1992) Review and Critique of DSS, in Information Systems and Decision Processes (eds. E. Stohr and B. Konsynski) IEEE Computer Society Press, Los Alamitos, California.

Kraemer, J. and King, J. (1988) Computer-based systems for cooperative work and group decision making. ACM Computing Surveys, 20, 115-146.

Langley, A. (1989) In search of rationality: the purposes behind the use of formal analysis in organisations. Administrative Science Quarterly, 34, 598-631.

Lyytinen, K., Maaranen, P. and Knuuttila, J. (1994) Groups are not always the same: An analysis of group behaviours in electronic meeting systems. CSCW: An International Journal, 2, 263-286.

Mackay, W. (1990) Users and Customizable Software: A Co-Adaptive Phenomenon. Doctoral dissertation, Sloan School of Management, MIT.

March, J. (1991) How decisions happen in Organizations. Human - Computer Interaction, 6, 95-117. 
Marshak, D. (1990) Lotus Notes: A platform for developing workgroup applications. Patricia Seybold's Office Computing Report, 13, 7(July), 1-14.

McDermott, R., Gospodinoff, K. and Aron, R. (1978) Criteria for an ethnographically adequate description of concerted activities and their contexts. Semiotica, 24, 245-275.

Nunamaker, J., A. Dennis, J. Valacich, D. Vogel, and J. George, (1991). Electronic Meeting Systems to Support Group Work. Communications of the $A C M, 34,40-61$.

Orlikowski, W. (1992) Learning from Notes: Organizational Issues in Groupware Implementation, in Proceedings of CSCW'92, Toronto.

Poole, M.S. and DeSanctis, G. (1989) Use of group decision support systems as an appropriation process, in Proceedings of the Twenty-Second Annual Hawaii International Conference on System Sciences, Vol. IV, 149-157.

Preston, A. (1991) The "problem" in and of management information systems. Accounting, Management, and Information Technology, 1, 43-69.

Robinson, M. and Bannon, L. (1991) Questioning Representations, in Proceedings of the Second European Conference on CSCW (eds. L. Bannon, M. Robinson, and K. Schmidt). Kluwer, Dordrecht.

Sachs, P. (1995) Transforming Work: Collaboration, Learning and Design. Communications of the ACM, 38, 36-44.

Savage, C. M. (1987) Fifth Generation Management for Fifth Generation Technology ( A Round Table Discussion), Society of Manufacturing Engineers, Dearborn, Michigan.

Schmidt, K. (1990) Analysis of Cooperative Work. A Conceptual Framework. Risø-M-2890. Risø National Laboratory, Roskilde, Denmark.

Schmidt, K. (1991). Riding a Tiger, or Computer Supported Cooperative Work, in Proceedings of the Second European Conference on CSCW (eds. L. Bannon, M. Robinson and K. Schmidt) Kluwer, Dordrecht.

Schmidt, K. and Bannon, L. (1992). Taking CSCW Seriously: Supporting articulation work. Computer Supported Cooperative Work, 1, 7-40.

Stohr, E. and Konsynski, B. (1992) Information Systems and Decision Processes. IEEE Computer Society Press, Los Alamitos, California.

Strauss, A. (1985) Work and the Division of Labor. The Sociological Quarterly, 26, 1-19.

Suchman, L. (1987). Plans and situated actions: The problem of human-computer communication. Cambridge University Press, Cambridge.

Tatar, D., G. Foster, and D. Bobrow, (1991). Design for Conversation: Lessons from Cognoter, in Computer-supported Cooperative Work and Groupware (ed. S. Greenberg )

Whitaker, R. (1992). Venues for Contexture: A critical analysis and enactive reformulation of group decision support systems, UMADP-RRIPCS 15.92, Dept. of Information Processing, Umeå University, Sweden. 
Whitaker, R. (1994) GDSS' Formative Fundaments: An Interpretive Analysis. CSCW: An International Journal, 2, 241-262.

Winograd, T. and Flores C. F. (1986) Understanding computers and cognition: A new foundation for design. Ablex, Norwood, N. J.

\section{BIOGRAPHY}

Liam Bannon is Director of the Interaction Design Centre, which includes the Computer Supported Cooperative Work (CSCW) Centre, and Senior Lecturer in the Department of Computer Science and Information Systems at the University of Limerick. His research interests include human-computer interaction, CSCW, multimedia design, and social and organizational aspects of computing. He is involved with IFIP Working Groups 8.2, 8.3, 8.6 and is an editor of the CSCW Journal. Previous publications include Perspectives on the Computer Revolution (1989) (with Z. Pylyshyn) and Information Technology: Impact on the way of life (1982) (with U. Barry and O. Holst). 